\title{
Primary and secondary esophageal contractions in patients with gastroesophageal reflux disease
}

C.G. Aben-Athar and R.O. Dantas
Departamento de Clínica Médica, Faculdade de Medicina de Ribeirão Preto, Universidade de São Paulo, Ribeirão Preto, SP, Brasil

\section{Correspondence}

R.O. Dantas

Departamento de Clínica Médica FMRP, USP

Av. Bandeirantes, 3900

14049-900 Ribeirão Preto, SP

Brasil

Fax. +55-16-3633-6695

E-mail: rodantas@fmrp.usp.br

Publication supported by FAPESP.

Received November 8, 2005 Accepted May 31, 2006

\begin{abstract}
We studied the primary and secondary esophageal peristalsis in 36 patients with heartburn and acid regurgitation and in 14 asymptomatic volunteers. Primary peristalsis was elicited by ten swallows of a 5-mL bolus of water and secondary peristalsis was elicited by intra-esophageal infusion of 5, 10, and $15 \mathrm{~mL}$ water, $0.1 \mathrm{~N}$ hydrochloric acid and air. Esophageal contractions were measured by an 8-lumen manometric catheter assembly incorporating a 6-cm sleeve device. Contractions were registered at 3,9 , and $15 \mathrm{~cm}$ from the upper margin of the sleeve and the infusion was done through a side hole located at $12 \mathrm{~cm}$. Twenty patients had normal endoscopic esophageal examination, 10 with normal (group I) and 10 with abnormal $\mathrm{pH}$-metric examination (group II), and 16 had esophagitis (group III). The amplitude of contractions after swallows was lower $(97.8 \pm 10.0 \mathrm{mmHg})$ in the distal esophagus of group III patients than in controls (142.3 \pm 14.0 $\mathrm{mmHg}$ ). Patients of group III had fewer secondary contractions (water: $25 \%$ of infusion) than patients of the other groups and controls (67\% of infusion). Patients of group III also had a lower amplitude of secondary peristalsis in the distal esophagus (water: $70.1 \pm 9.6 \mathrm{mmHg}$ ) than controls $(129.2 \pm 18.2 \mathrm{mmHg})$. We conclude that patients with esophagitis have an impairment of primary and secondary peristalsis in the distal esophagus.
\end{abstract}

\section{Introduction}

Esophageal contractions are the best way to clear the esophagus of refluxed material from the stomach. The esophageal body responds to reflux by an increase in primary peristalsis through stimulation of swallowing and by secondary peristalsis through esophageal distension (1). However, esophageal peristalsis is affected by reflux (2-4) and inadequate peristalsis contributes significantly to the development of esophageal
Key words

- Esophageal contractions

- Gastroesophageal reflux disease

- Esophagitis

- Heartburn

- Esophageal motility injury and esophagitis $(5,6)$. It is possible that the impairment of esophageal contractions affects both primary and secondary peristalsis. Postprandial upright gastroesophageal reflux is mainly cleared by primary swallow-induced peristalsis, whereas secondary distention-induced peristalsis seems to play a more relevant role after supine reflux (1).

The objective of the present study was to evaluate the primary and secondary peristalsis elicited by intraesophageal infusion of 
different volumes of air, water and $0.1 \mathrm{~N}$ hydrochloric acid $(\mathrm{HCl})$ in patients with gastroesophageal reflux symptoms.

\section{Material and Methods}

We studied 36 patients with heartburn and acid regurgitation and 14 asymptomatic volunteers. The patients with heartburn were 13 men and 23 women aged 16 to 64 years (median: 40 years). Twenty patients had normal esophageal endoscopic examination, 10 with a normal score, $<14.72(7,8)$ in $24-h$ pH-metric examination (group I), and 10 with an abnormal score, $>14.72$ (group II). Sixteen patients had esophagitis detected by endoscopic examination (group III), 7 of them with grade I, 5 with grade II and 4 with grade III of the Savary-Miller classification (9). The proportion of patients with symptoms occurring more than once a week was 80,78 , and $81 \%$ in groups I, II and III, respectively. The symptoms were classified as severe in $50 \%$ of group I patients, $44 \%$ of group II patients and $56 \%$ of group III patients.

The control group included 14 asymptomatic volunteers ( 2 men) without symptoms or treatment for esophageal diseases, aged 20 to 54 years (median: 38 years). The study was approved by the Human Research Committee of the University Hospital of Ribeirão Preto and all subjects gave written informed consent to participate in the study.

Esophageal manometry was performed using an 8-lumen manometric catheter assembly incorporating a 6-cm sleeve device at its distal end (10). Side-hole recording orifices were cut at the distal and proximal margins of the sleeve. Five additional sidehole recording orifices were cut at $3-\mathrm{cm}$ intervals along the assembly, starting $3 \mathrm{~cm}$ proximal to the sleeve (Arndorfer Specialties Inc., Greendale, WI, USA). The catheter assembly was connected to external pressure transducers (pvb Medizintechnik, Munich, Germany), which in turn were con- nected to a PC Polygraph HR (Synectics Medical, Stockholm, Sweden). The manometric signals were stored in a computer. During the manometric recordings, a minimally compliant pneumohydraulic pump (JS Biomedicals Inc., Ventura, CA, USA) perfused distilled water at $0.5 \mathrm{~mL} / \mathrm{min}$ through the sleeve and the side holes.

Each subject was studied after an overnight fast. The catheter assembly was passed through the nose and positioned so that the 6-cm long sleeve straddled the lower esophageal sphincter. The contractions in the esophageal body were recorded by the side holes located at 3, 9, and $15 \mathrm{~cm}$ from the upper margin of the sleeve, about 5, 11, and $17 \mathrm{~cm}$ from the upper margin of the lower esophageal sphincter. All volunteers and patients were studied in the supine position. In the study of primary peristalsis subjects performed 10 swallows of a 5 -mL bolus of water at room temperature with an interval of at least $30 \mathrm{~s}$ between successive swallows. For secondary peristalsis we injected within $6 \mathrm{~s}$ in duplicate through the side hole located $12 \mathrm{~cm}$ from the upper margin of the sleeve 5 , 10 , and $15 \mathrm{~mL}$ water, 5,10 , and $15 \mathrm{~mL} 0.1 \mathrm{~N}$ $\mathrm{HCl}, \mathrm{pH} 1.8$, and 5, 10, and $15 \mathrm{~mL}$ air in this sequence, with a minimum interval of at least $20 \mathrm{~s}$ between infusions. If the patient or volunteer performed a spontaneous swallow before $20 \mathrm{~s}$ after infusion the response was not measured. Secondary contractions were observed when there was an esophageal contraction within $20 \mathrm{~s}$ after water, $\mathrm{HCl}$, or air infusion. The interval of $20 \mathrm{~s}$ after each infusion was permitted for any response to occur.

Using the computer Polygram Upper GI software version 6.4 (Gastrosoft Inc., Stockholm, Sweeden) we measured the amplitude, duration, area under the curve, and velocity of peristaltic contractions.

Peristalsis was observed when the wave migrated aborally with a time delay between the contraction phase at each successive level of recording in the esophageal body (8) 
Simultaneous contraction occurred when there was no time delay between the contraction phases at each level of recording. Failure occurred when there was an absence of contraction after the intraesophageal infusion, and non-conducted contraction occurred when there was an interrupted propagation in the upper/mid-esophagus.

For statistical analysis we used one-way analysis of variance, the Tukey-Kramer test for multiple comparisons when the Kolmogorov-Smirnov test indicated that the results followed a Gaussian distribution, the Kruskal-Wallis and the Dunn tests for multiple comparisons when the results did not show Gaussian distribution, and the Fisher test. The results are reported as mean \pm SEM, and percentage.

\section{Results}

In 38\% of esophagitis patients of group III less than $80 \%$ of swallows were followed by peristaltic contractions, in contrast to the control group, in which all subjects had more than $80 \%$ of peristaltic contractions after swallows $(\mathrm{P}<0.05)$.

The amplitude of contractions after wet swallows was lower in the distal esophagus of patients with esophagitis (group III) (97.8 $\pm 10.0 \mathrm{mmHg})$ than in controls $(142.3 \pm 14.0$ $\mathrm{mmHg}, \mathrm{P}<0.05)$. There was no difference between groups in the duration of contraction, area under the curve or peristaltic velocity $(\mathrm{P}>0.05)$.

The infusion of a 5-mL volume of water, $\mathrm{HCl}$ and air caused a small number of secondary contractions. Since there was no difference between the volumes of 10 and 15 $\mathrm{mL}$, we analyzed the two volumes together.

The percentage of secondary contractions caused by intraesophageal infusion of water, was $67 \%$ in the control group and $25 \%$ in the group III patients. Patients with esophagitis (group III) had less secondary peristaltic contractions than patients of groups $\mathrm{I}$ and II and controls (Figure 1; P $<0.05$ ).
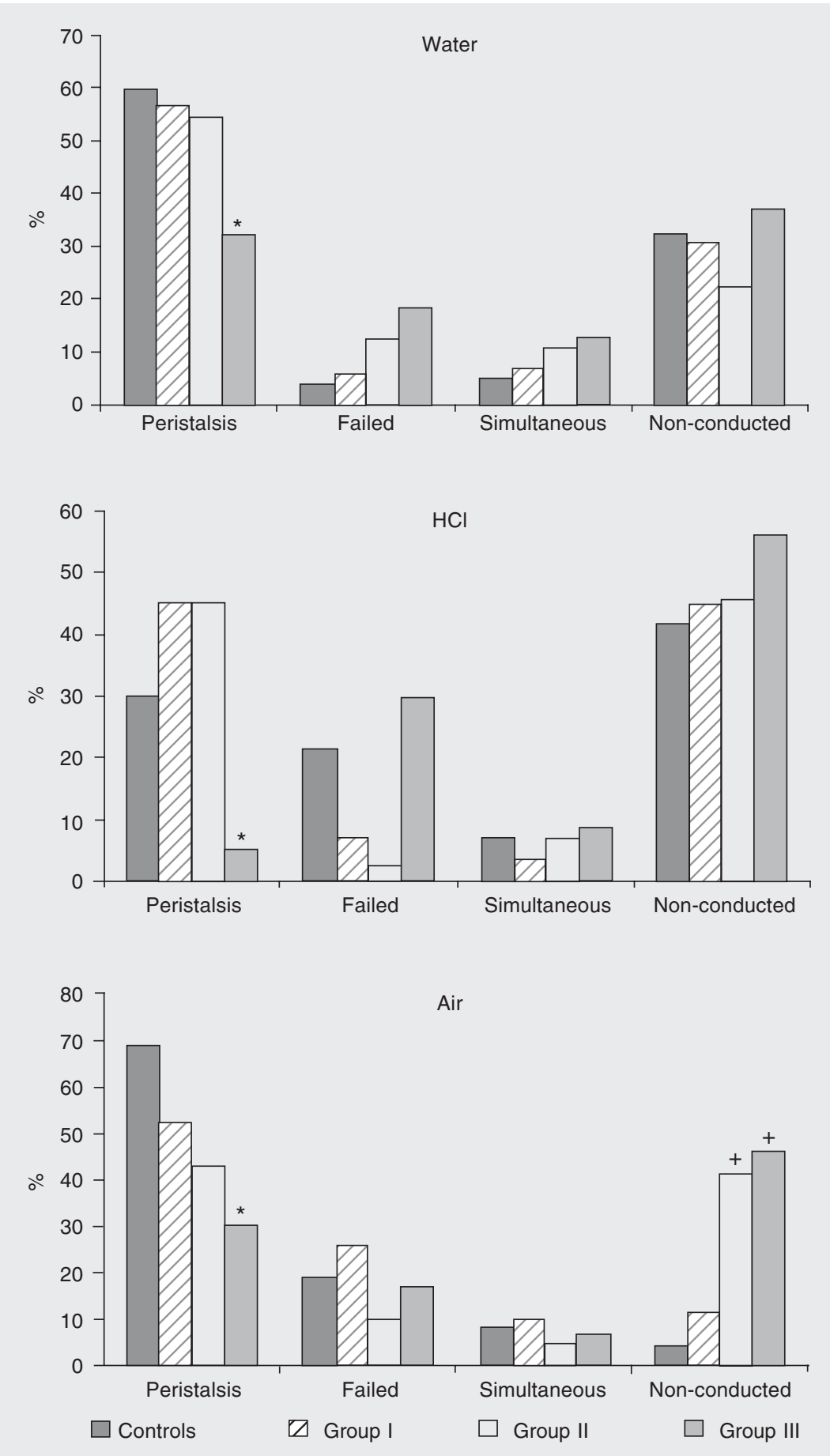

Figure 1. Percentage of secondary esophageal peristaltic (time delay between the contraction phase at each sucessive level of recording), failed (absence of contraction), simultaneous (no time delay between the contraction phase), or non-conducted (interrupted propagation) contractions elicited by intraesophageal infusion of water, $\mathrm{HCl}$ and air. ${ }^{*} \mathrm{P}<$ 0.05 compared to controls and groups I and II. ${ }^{+} \mathrm{P}<0.05$ compared to controls and group I (Fisher test). 
There were no significant differences between groups in terms of the consequences of infusion of water, $\mathrm{HCl}$ or air.

The patients of group III had a lower amplitude (water: $70.1 \pm 9.6 \mathrm{mmHg}, \mathrm{HCl}$ : $43.3 \pm 7.8 \mathrm{mmHg}$ ) of secondary contractions at $3 \mathrm{~cm}$ from the lower esophageal sphincter than controls (water: $129.2 \pm 18.2 \mathrm{mmHg}$, $\mathrm{HCl}: 123.8 \pm 34.2 \mathrm{mmHg}, \mathrm{P}<0.05)$.

\section{Discussion}

We observed that patients with esophagitis have a lower amplitude of primary and secondary contractions in the distal esophageal body and a lower proportion of secondary peristalsis than control subjects.

The esophageal contractions are an important factor in the clearing of reflux material from the esophagus $(11,12)$. The major acid clearance mechanism is primary peristalsis (13), while secondary peristalsis has a less important role (1).

Low contraction amplitude and an increased number of failed contractions are seen in patients with gastroesophageal reflux disease (GERD) (5). These alterations in the distal esophagus do not delay the arrival of saliva to the distal esophageal body but prolong the clearance to the stomach in the supine position (14). In this situation the subjects may have more frequent and intense esophageal lesions caused by gastroesophageal reflux.

Olsen and Schlegel (3) described the relationship between esophageal motility alterations and esophagitis, with an ineffective peristalsis seen in $32 \%$ of the patients studied, as later confirmed by others $(5,15)$. Distal esophageal contraction amplitude is lower than normal in patients with GERD (5) and in animals with experimentally induced esophagitis (16).

We do not know whether gastroesophageal reflux leads to the development of distal low contraction amplitude by repeated distal esophageal acid exposure or whether the presence of preexisting poor esophageal contractions leads to ineffective esophageal clearance mechanisms, causing esophagitis $(5,6)$. This esophageal motility impairment appears to be irreversible by clinical or surgical treatment (17), suggesting that it is a cause and not a consequence of prolonged acid exposure. However, a small increase in esophageal contraction amplitude may be seen in the esophagus after the healing of esophagitis (2).

The lower frequency of secondary peristalsis after gastroesophageal reflux in patients with esophagitis suggests that there may be a defect of the triggering of secondary peristalsis in these patients. Previous studies have suggested that patients with GERD lose the ability to lower the threshold for triggering secondary peristalsis in response to an acid stimulus (18). Rapid and brief esophageal distentions with air and water have revealed a defect in the triggering of secondary peristalsis in these patients (19). The secondary peristaltic response rates were lower in patients with GERD than in controls, and most patients exhibited no response (16). Our results confirm these observations. However, in contrast to a previous study (1), we found a low contraction amplitude in the distal esophageal body during secondary peristalsis in patients with esophagitis, a result similar to that observed in primary peristalsis. Esophageal acidification itself has little or no effect on esophageal motility (1), representing further evidence that the motility impairment precedes the gastroesophageal reflux.

The volume of $5 \mathrm{~mL}$ was not sufficient to trigger secondary peristalsis. The volumes of 10 and $15 \mathrm{~mL}$ elicited similar responses in terms of frequency of triggering secondary contractions and amplitude. Water seems to be the best stimulus of esophageal distention triggering secondary contractions.

Spontaneous reflux episodes causing secondary peristalsis occurred less frequently after reflux in patients with esophagitis than 
in normal subjects (20). The defect may lie in the esophageal motor nerves or muscles, esophageal sensation, the central integrative mechanism, or a combination of these (19). It has been suggested that the defect in secondary peristalsis is due to an abnormality of esophageal sensation or in the integration of sensory information with the motor component of the reflex (19).

Secondary peristalsis can effectively clear almost all of an injected acid bolus from the esophagus, leaving a small residual volume (11). It occurs in almost half of the reflux episodes in normal subjects (20). The clearance of acid volume from the distal esophagus may be compromised by the low contraction amplitude but the acid neutraliza- tion by saliva, that occurs with primary peristalsis, may be normal (14).

Patients of group I had functional heartburn and their results were similar to those of the control subjects. Functional heartburn has different pathophysiological characteristics from those of non-erosive reflux disease (group II). Group II had results similar to those of patients with esophagitis (group III). Patients with functional heartburn do not have reflux disease, a fact explaining the reportedly low efficacy of proton pump inhibitors in these patients (21).

In conclusion, the results showed that patients with esophagitis have an impairment of primary and secondary peristalsis in the distal esophagus.

\section{References}

1. Holloway $\mathrm{RH}$. Esophageal body motor response to reflux events: secondary peristalsis. Am J Med 2000; 108 (Suppl 4a): 20S-26S.

2. Deprez $P$, Fiasse R. Healing of severe esophagitis improves esophageal peristaltic dysfunction. Dig Dis Sci 1999; 44: 125-133.

3. Olsen AM, Schlegel JF. Motility disturbances caused by esophagitis. J Thorac Cardiovasc Surg 1965; 50: 607-612.

4. Mearin F, Vasconez C, Zarate N, Malagelada JR. Esophageal tone in patients with total aperistalsis: gastroesophageal reflux disease versus achalasia. Am J Physiol Gastrointest Liver Physiol 2000; 279: G374-G379.

5. Kahrilas PJ, Dodds WJ, Hogan WJ, Kern M, Arndorfer RC, Reece A. Esophageal peristaltic dysfunction in peptic esophagitis. Gastroenterology 1986; 91: 897-904.

6. Kahrilas PJ, Dodds WJ, Hogan WJ. Effect of peristaltic dysfunction on esophageal volume clearance. Gastroenterology 1988; 94: 7380 .

7. Johnson LF, DeMeester TR. Twenty-four-hour pH monitoring of the distal esophagus. A quantitative measure of gastroesophageal reflux. Am J Gastroenterol 1974; 62: 325-332.

8. Evans DF, Buckton GK. Clinical measurement in gastroenterology. Vol. 1. The oesophagus. Oxford: Blackwell Science; 1997.

9. Ollyo JB, Fontolliet C, Brossard E. La nouvele classification de Savary des oesophagites de reflux. Acta Endoscopica 1992; 22: 307-320.

10. Miranda AL, Dantas RO. Esophageal contractions and oropharyngeal and esophageal transits in patients with iron deficiency anemia. Am J Gastroenterol 2003; 98: 1000-1004.

11. Helm JF, Dodds WJ, Riedel DR, Teeter BC, Hogan WJ, Arndorfer RC. Determinants of esophageal acid clearance in normal subjects. Gastroenterology 1983; 85: 607-612.

12. Helm JF, Dodds WJ, Pelc LR, Palmer DW, Hogan WJ, Teeter BC.
Effect of esophageal emptying and saliva on clearance of acid from the esophagus. N Engl J Med 1984; 310: 284-288.

13. Anggiansah A, Taylor G, Bright N, Wang J, Owen WA, Rokkas T, et al. Primary peristalsis is the major acid clearance mechanism in reflux patients. Gut 1994; 35: 1536-1542.

14. Dantas RO, Oliveira RB, Aprile LR, Hara SH, Sifrim DA. Saliva transport to the distal esophagus. Scand J Gastroenterol 2005; 40: 1010-1016.

15. Jacob P, Kahrilas PJ, Vanagunas A. Peristaltic dysfunction associated with nonobstructive dysphagia in reflux disease. Dig Dis $\mathrm{Sci}$ 1990; 35: 939-942.

16. Sinar DR, Fletcher JR, Castell DO. Acute esophagitis adversely affects esophageal peristalsis. Clin Res 1980; 28: 221A.

17. Timmer R, Breumelhof R, Nadorp JH, Smout AJ. Oesophageal motility and gastro-oesophageal reflux before and after healing of reflux oesophagitis. A study using 24 hour ambulatory $\mathrm{pH}$ and pressure monitoring. Gut 1994; 35: 1519-1522.

18. Corazziari E, Materia E, Pozzessere C, Anzini F, Torsoli A. Intraluminal $\mathrm{pH}$ and oesophageal motility in patients with gastro-oesophageal reflux. Digestion 1986; 35: 151-157.

19. Schoeman MN, Holloway RH. Integrity and characteristics of secondary oesophageal peristalsis in patients with gastro-oesophageal reflux disease. Gut 1995; 36: 499-504.

20. Dodds WJ, Kahrilas PJ, Dent J, Hogan WJ, Kern MK, Arndorfer RC. Analysis of spontaneous gastroesophageal reflux and esophageal acid clearance in patients with reflux esophagitis. $J$ Gastrointest Motil 1990; 2: 79-89.

21. Frazzoni M, De Micheli E, Zentilin P, Savarino V. Pathophysiological characteristics of patients with non-erosive reflux disease differ from those of patients with functional heartburn. Aliment Pharmacol Ther 2004; 20: 81-88. 